NOTEC:

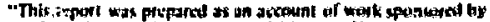

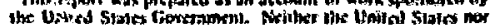

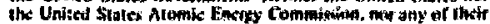

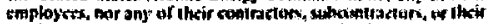

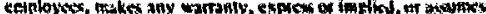

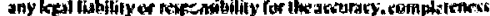

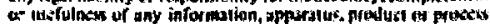

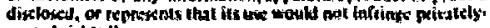
Derrod ringts"

Printed in the United States of America Available from

National Technical Information Service

U,S. Department of Commerce 5285 Port Royal Road Springifeld, Virginia 221.51

Price: Printed Copy $\$$; Microfiche \$0.95

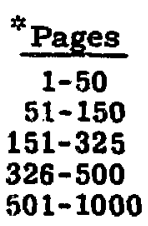

NTIS

Salling Price

$\$ 4.00$

$\$ 5.45$

$\$ 7.60$

$\$ 10.60$

501-1000

$\$ 13.60$ 
TID-4500, UC-34C

Nuclear Physics

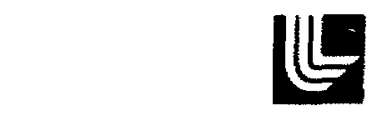

LAMRENCE UNERMARE LAEORATOFY

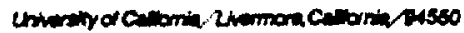

UCRL-51AŻT

EVALUATED NEUTRON REACTION DATA FOR URANIUM 238

R. J. Howerton

M. H. MacGregar

MS. date: March 21, 1973

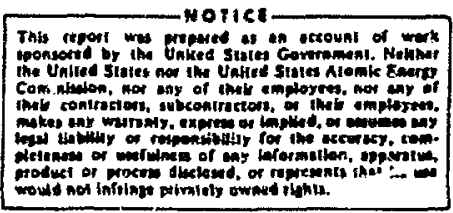




\section{Contents}

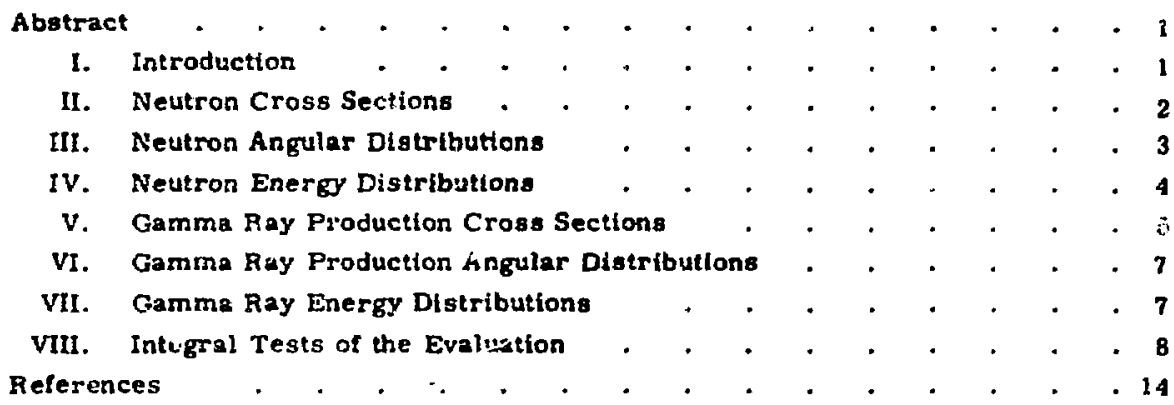




\title{
EVALUATED NEUTRON REACTICN DATA FOR URANIUM 238
}

\author{
Abstract \\ Describes methor's used to obtain \\ evaluated neutron interaction and photon \\ production data for ${ }^{238} \mathrm{U}$.
}

\section{Introduction}

This report describes the procedures used to obtain evaluated neutron interaction and photon production data for ${ }^{238} \mathrm{U}$ for the neutron energy range from $10 \mu \mathrm{V}$ to $20 \mathrm{MeV}$. The evaluation is designated as MAT 4187 in the DNA evaluated nuclear data collection obtainable from the Radiation Shielding information Center, Oak Ridge National Laboratory. In this energy range a number of nonelastic reactions are energetically possible in addition to elasitic scattering. Table 1 lists these reactions and ticeir thresholds.

This evaluation neglects all of the charged-particle-producing reactions, both because there are essentially no measurements and because the Coulomb barrier suppression leads to very small cross sections. The reactions that are included in the evaluated data set, in addition to total and elastic cross sections, are tutal nonelastic, $\left\{n, n^{\prime}\right),(n, 2 n),(n, 3 n)$, $(n, 4 n),(n, r),(n, f i s s i o n)$, anc: $(n, X \gamma)$.

The present report is divided into the following sections:
II. Neutro' $\downarrow$ crisss sections

III. Neutron angular distributions

IV. Neutron energy distributions

V. Gamina-ray production cross sections

VI. Gammia-ray production angular distributions

VII. Gamma-ray production energy distributions

VIII. Integral tests of the evaluation

Each section includes a discussion of errors.

Tabie 1. Neutron interaction and photon production reactions and thresholds for $238 \mathrm{U}$.

\begin{tabular}{cc}
\hline Reaction & Threshold (MeV) \\
\hline n, n' & 0.0452 \\
n, 2n & 6.17 \\
n, 3n & 11.32 \\
n, 4n & 17.89 \\
n, $p$ & 3.19 \\
n, np & 7.69 \\
n, d & 5.46 \\
n, nd & 11.41 \\
n, & 5.13 \\
n, nt & 9.99 \\
n, fisaton & 0.45 \\
n, $\sigma$ & exoergic \\
n, $\gamma$ & $(Q \approx 9 \mathrm{MeV})$ \\
& exoergic \\
& $(Q=30 \mathrm{MeV})$
\end{tabular}

Work performed under the ausplces of the Defense Nuclear Agency and the U,S. Atomic Energy Commission. 


\section{Neutron Cross Sections}

\section{A. Total Cross Section}

Total cross section measurements ${ }^{1-23}$ exist over the entire energy range of interest. In the energy region below $1 \mathrm{keV}$, ENDF/B-III MAT 1158 data were used, with temperature broadening to $300^{\circ} \mathrm{K}$ and deletion of some data points based on a $10 \%$ thinning criterion. No resonance parameter data are included explicitly in the evaluation. Individual total cross section dais points have quoted errors ranging from about $1 \%$ to $10 \%$. The evaluat. $d$ total crcss section curve has an estimated accuracy of $5 \%$ to $: 0 \%$.

\section{B. Nonelastic Cross Section}

Nonelastic cross section measurements ${ }^{24-33}$ span the energer range from $0.15 \mathrm{MeV}$ to $18.5 \mathrm{MeV}$, and they include measurements made by one of us (M.H.M., Ref. 30). For neutron energies greaier than about $4 \mathrm{MeV}$. the nonelastic cross section is quite cor.stant with energy. The quoted errors are about $10 \%$ to $20 \%$ at the lower energies and $5 \%$ to $10 \%$ at the higher energies. The evaluated nonelastic cross section curve has an accuracy of $15 \%$ at the lower energies and $10 \%$ at the higher energies.

\section{Elastic Cross Section}

Experimental measurements of the elastic cross section ${ }^{14,18,34}$ have been made between $0.3 \mathrm{MeV}$ and $4 \mathrm{MeV}$ and at 7 and 14.1 MeV. At higher and lowar energies, the elastic cross section was determined from systematics and from the differences between measured values for the toial and nonelastic cross sections. At energies below $1 \mathrm{keV}$. the elastic cross section was based on ENDF: $B$ MAT 1158 data, with the Jata temperature-broadened to $300^{\circ} \mathrm{K}$ and thinned using a $10^{\circ}$; thinning criterion. The thermal neutron elastic scattering cross section is 8 barns (b), as jetermined by the difference between the total cross section and the capture crose section. Taking into account the errors attributed to the total cross sections and the nonelastic cross sections, we estimate accuracies for the elastic cross sections of about $15 \%$.

\section{Fartial Nonelastic $C_{1}$.jss Sections} These include the $(n, y)$, ( $n$, fission), $(n, n),(n, 2 n),(n, 2 n),(n, 3 n)$, and $(n, 4 n)$ reactions.

\section{$(\mathrm{n}, \gamma)$ Reaction}

Measurements of the $(n, \gamma)$ cross section ${ }^{35-62}$ have been made from thermal energies to $7.6 \mathrm{MeV}$ and $\mathrm{a} \hat{\imath} 14.5 \mathrm{MeV}$. At energies below $1 \mathrm{keV}$, the ( $\mathrm{n}, \gamma$ ) cross section was based on ENDF/B MAT 1158 data, with the data temperature-broadened to $300^{\circ} \mathrm{K}$ and thinned using a $20 \%$ thinning criterion. Since the magnitude of the (n, $-f$ ) cross section above $7.6 \mathrm{MeV}$ is less than $10 \mathrm{mb}$, any reasonable highenergy extrapolation is adequate for the evaluation. The estimated uncertainty in the $(n, \gamma)$ cross section is $5 \%$ or less at thermal energies, about $25 \%$ in the epithermal and keV range, and perhaps $15 \%$ in the $\mathrm{MeV}$ range up to $14 \mathrm{MeV}$.

\section{(n, fission) Reaction}

Measurements of the ( $n$, fission) cross section $^{63-84}$ span the energy region from threshold to $20 \mathrm{MeV}$. These measure- 
ments have an accuracy, relative to the 235 [i rission cross section, of about $5 \%$. Since the ${ }^{235} \mathrm{U}$ fission cross section has estimated uncertainties of about $5 \%$ at low and moderate energies and $10 \%$ at $14 \mathrm{MeV}$, the overall uncertainties in the ${ }^{238} \mathrm{U}$ fission cross sections are slightly larger than tiose for ${ }^{235} \mathrm{U}$.

$\left(n, n^{\prime}\right)$ Reaction

Since ${ }^{238} U$ is an even-even nucleus, it has a relatively small number of lowlying levels. For neutron energies up to $4 \mathrm{MeV}$ the eval ation includes $\left(n, n^{2}\right)$ excitations to several discrete lines plus an $\left(n, n^{\prime}\right)$ continuum contribution, with the results based on experimental da:a. $14,24,26,34,85-90$ Above $4 \mathrm{MeV}$ only the continuum component is considered, and the evaluated cross sections are based on nuclear systematics. The $\left(n, n^{\prime}\right)$ evaluatec cross sections have accuracies of about $25 \%$ below $4 \mathrm{MeV}$ and $40 \%$ above $4 \mathrm{MeV}$.

\section{(n, 2n) Reaction}

Uranium-238 is the only high- $Z$ isotope for which the $(n, 2 n)$ excitatic function has oeen accurately measured. $86,91-96$ The evaluated $(n, 2 n)$ cross section was based on experimental data from $6.4 \mathrm{MeV}$ to $16 \mathrm{MeV}$, and nuclear systematics were used to extend the evaluation to $20 \mathrm{MeV}$. The experimental (n, 2n) data have quoted errors of $5 \%$ to $10 \%$. The accuracy of the $(n, 2 n)$ evaluation is $10 \%$ over most of the energy range, with somewhat larger uncertainties near threshold and above 16 MeV.

\section{(n, 3n) Reaction}

The $(n, 3 n)$ cross section has been measured in the energy range from $12,6 \mathrm{MeV}$ to $18.8 \mathrm{MeV} .86,87,89,92,93$ These measurements were combined with nuclear systematics to span the range of evaluaced energies. The quoted experimental errors range from about $25 \%$ to $50 \%$, and the evaluation has an accuracy of about $50 \%$.

\section{(n, 4n) Reaction}

Two (n, 4n) data points exist, ${ }^{89}$ at 17.8 MeV and $18.8 \mathrm{MeV}$. These were combined with nuclear systematics to complete the evaluation. The data $p$, nts have quoted errors of $40 \%$ and $100 \%$, and the evaluation for the $(n, 4 n)$ cross section has an accuracy that is comparable with these experimental accuracies.

\section{Neutron Angular Distributions}

A. Elastic Scattering Angular Distributions Experimental measurements of elastic scattering angular distributions have been made from $0.075 \mathrm{MeV}$ to $4 \mathrm{MeV}$ and at 7 and $14.1 \mathrm{MeV} .14,18,34,89$ These were combined with optical model calculations to cover the range of energies needed for the evaluation. The total elastic cross section has an accuracy of about $15 \%$, and the individual differential cross section data points have relative uncertainties of about $: 5 \%$.

B. Nonelastic Scattering Angular Distribution

A number of measurements have been made on $\left(n, n^{\prime}\right)$ angular distributions. $14,97-i 00$ 
However, except for the lowest $\left(n, n^{\prime}\right)$ level $(0, n: 1 ; \mathrm{MeV})$, these indicate that the $\left(n, n^{\prime}\right)$ scattering is essentially isotropic. Hence the lowest $\left(n, n^{\prime}\right)$ level was entered with anisotropic angular distributions, but all other inelastic processes were assumed to be isotropic. This assumption of isotropy leads to no more than $10 \%$ ti $15 \%$ errors in the worst cases for $(n, 2 n),(n, 3 n)$, and $(n, 4 n)$ reactions, but high energy $\left(n, n^{\prime}\right)$ reactions may have larger errors than this since they tend to exhibit a forward peaking.

\section{Neutron Energy Distributions}

The formalism that was used to specify the nonelastic neutron spectra is described individually for eich reaction. Although murh of the follewing discussion is couched in terins of the evaporation model, the $\in$ nergy distributions are presented exclusively as tables. Since not all distributions can be represented in the evaporysiun formalism but all can be represented by tables, a tabular representation preserves consistency. A minor but pertinen: point is the choosing of the low enerity cut-off if nuclear temperatures are presented. The tabular representation makes the intended use of the data explicit.

\section{A. (n, fission) Energy Distr butions arido (E) \\ Measuremerits of the neutron energy} spectrum from fission have been made at only two energies. ${ }^{101}$ However, fission spectra can be obtained at all energies by using the formalism given in papers by Howerton $^{102}$ and by Howerton and Doyas. 103 The first of these papers ${ }^{102}$ gives a method of predicting the value of $\vec{v}(E)$, where $\vec{\nu}(E)$ is the average number of neutrons emitted p: $r$ fission at neutron enej.gy $E$, and the second paper ${ }^{103}$ gives the fission temperature as a function of $\bar{v}$.
Thus a combination of these two calculations gives the fission energy spectrum for all incident neutr i energies. The slope of the energy dependence of $\bar{v}$ changes as the thresholds corresponding to ( $n, n^{\prime}$ fission), ( $n, 2 n$ fission), etc., are reached. Hence in the evaluation, the fission neutron energy spectra are quoted at energies that correspond to thresholds and to midpoints between thresholds.

Many measurements have been made of the value of $\overrightarrow{\nu(E)}$ that corresponds to prompt neutron emission. 77,92,104-124 These measurements are implicitly incorporated into the formalism of Howerton. ${ }^{102}$ In particular, values for $\bar{v}(E)$ that were predicted on the basis of the Howerton formalism are in good agreement with experimental values ${ }^{111}$ that were measured subsequent to the predictions. The experimental data extend up to $14.8 \mathrm{MeV}$, and systematics was used to extend these results to $20 \mathrm{MeV}$.

The neutron energy spectrum from fission is known to an accuracy of about $5 \%$ over the secondary neutron energy range from $0.5 \mathrm{MeV}$ to $5 \mathrm{MeV}$. At lower and higher anergies, it is known to about $10 \%$. The accuracy of $\bar{\nu}$ is estimated to about $2 \%$. 
B. $\left(n, n^{\prime}\right)$ Energy Distributions

For neutron energies below $4 \mathrm{MeV}$, $\left(n, n^{\prime}\right)$ energy distributions were obtained from experimental measurements. $14,34,97-99$ For neutron energies above $4 \mathrm{MeV}$, the $\left(n, n^{\prime}\right)$ energy distributions were taken from a model that includes both a low en:rgy temperature component and a high energy tail. The high-energy tail, which includes about $15 \%$ of the inelasticallyscattered neutrons at $4 \mathrm{MeV}$ and essentially $100 \%$ of the neutrons at energies of $15 \mathrm{MeV}$ and above, consists of direct-interaction and pre-equilibrium neuirons, chosen in appropriate fractions. At high energies, if an $\left(n, n^{\prime}\right)$ reaction does not result in a final state neutron $n$ ' that carries away most of the energy, then the residual nucleus will be left in a highly-excited state, and it will undergo fission or emit another neutron which takes it out of the $\left(n, n^{\prime}\right)$ category. Hence the high energy component of the $\left(n, n^{\prime}\right)$ reaction yields high energy neutrons almost exclusively. The energy spectrum has an accuracy of about $50 \%$ at lower energies and $100 \%$ at higher energies.

\section{C. $(n, 2 n)$ Energy Distributions}

No measuremerits exist for ( $n, 2 n)$ energy spectra in ${ }^{238} \mathrm{U}$. Hence a temperature model was used to provide these spectra. The spectrum was assumed to be the same for both the first and second neutrons, and it was chosen so that energy is conserved on the average, taking into account the energy that appears in the form of gamma rays. Even with the constraint imposed by the conservation of energy, errors can be large for certain portions of the energy spectrum and at certain incident neutron energies, ranging from perhaps $30 \%$ in favorable cases to orders of magnitude in unfavorable cases.

\section{D. $(n, 3 n)$ and $(n, 4 n)$ Energy Distributions}

The formalism used for (n, 2n) energy spectra was carried over directly to (n, $3 n$ ) and (n, 4n) energy spectra in the absence of data. Energy conservation again served as a constraint, but the errors can be even larger than for (n, 2n) reactions, since more complex decay modes are involved.

\section{Gamma Ray Production Cross Sections}

At neutron energies of $1.09 \mathrm{MeV}$ and above, comprehensive $(n, X \gamma)$ measurements exist ${ }^{125}$ which encompass all of the gamma-ray-producing reactions. For neutron energies below $1.09 \mathrm{MeV}$, gamma rays are produced by capture, fission, and $\left(n, n^{\prime}\right)$ processes. In the evaluation, the capture, fission, and $\left(n, n^{\prime}\right)$ gammaproducing reactions were explicitly included over the energy ranges from their various thresholds up to $1.09 \mathrm{MeV}$.
From 1.09 MEV to $20 \mathrm{MeV}$, the experimental ( $n, X \gamma$ ) cross sections ${ }^{125}$ were used, with some small modifications as noted below. An ( $\mathrm{n}, \mathrm{X} \gamma$ ) measurement at $0.3 \mathrm{MeV}$ also exists, ${ }^{125}$ but the shape of the energy spectrum does not agree well with other nearby measurements ${ }^{126}$ (at $0.3 \mathrm{MeV}$, the $(\mathrm{n}, \gamma)$ reaction is the only available gamma-producing process for photons with energy greater than $0.3 \mathrm{MeV}$ ). Also, and more importantly, the $0.3 \mathrm{MeV}$ 
gamma ray spectrum ${ }^{125}$ strongly violates energy conservation. For these reasons the $0.3 \mathrm{MeV}$ data ${ }^{125}$ were omitted from the evaluation.

\section{A. Gamma Ray Production from}

\section{Neutron Capture}

The capture gamma ray spectrum for ${ }^{238} \mathrm{U}$ has been accurately measured only at ther'mai neutron energies. ${ }^{127}$ Some measurements have also been made in the $\mathrm{eV}$ and low keV region. ${ }^{126}$ However, these measurements are made only at resonance energies, which may distort the results, and they have saveral obvious difficulties: (i) they disagree in spectral shape and in normalization with the very ccurate thermal measurement ${ }^{127}$; they extend only down to $1 \mathrm{MeV}$ photon energy, and their integrated spectral intensities suggest that the photon spectrum is very small below $1 \mathrm{MeV}-\mathrm{a}$ result that is known to be incorrect; (3) even with a lower energy photon cutoff at $1 \mathrm{MeV}$, some of the spectra violate energy conservation by as much as $30 \%$. With a reasonable low-energy photon component included, the normalization errors would be as large as 50\%. Errors of this magnitude indicate serious deficiencies in the experiment, and these deficiencies could affect both the shape and the normalization of the individual spectra. Thus the data of John and Orphan 126 were disregarded in the evaluation.

B. Gamma Ray Production and Fission Reactions The ${ }^{238} \mathrm{U}$ fission spectrum has a threshold at about $0.45 \mathrm{MeV}$. Since no measurements of the gamma rays from ${ }^{238_{U}}$ fission exist, the ${ }^{235_{U}} \mathrm{U}$ fission gamma ray spectrum ${ }^{129}$ was used for the evaluation. In the absence of data, the ${ }^{235} \mathrm{U}$ fission gamma ray multiplicity was also used for ${ }^{238} \mathrm{U}$, and this multiplicity was held constant for all neutron bombarding energies (since the neutron kinetic energy is negligible as compared to the fission energy releases, the constancy of the multiplicity with increasing neutron energy seems reasonable).

\section{Gamma Ray Production from (n, n') Reactions \\ The evaluated neutron data for ${ }^{238} \mathrm{U}$} include several experimentally-measured $\left(n, n^{\prime}\right)$ excitation levels, as was discussed in Section IID. The two lowest levels, at 50 and $150 \mathrm{keV}$, were carried in the evaluation as discrete lines from threshold up to $1.09 \mathrm{MeV}$. The $150 \mathrm{keV}$ decay was assigned a suitable branching ratio. 129 Gamma rays from the higher levels were placed in energy bins in a manner that conserves energy. The gamma rays from inelastic scattering are not as energetic as those from capture and fission. In the experimental ( $\mathrm{n}, \mathrm{X} \gamma$ ) data at $1.09 \mathrm{MeV},{ }^{125}$ the effect of these lowenergy ( $\left.n, n^{\prime}\right)$ gammas can be observed as causing the sharp rise in the $(n, X \gamma)$ cross section below $1 \mathrm{MeV}$. In fact, the proper shape for the low energy portion of the $1.09 \mathrm{MeV}\left(\mathrm{n}, \mathrm{X} \gamma\right.$ ) spectrum ${ }^{125}$ was determined by summing the ( $n, \gamma$ ), (n, fission). and $\left(n, n^{\prime}\right)$ contributions to the gamma ray spectrum at $1.09 \mathrm{MeV}$.

\section{Gamma Ray Production from $\left(n, X_{\gamma}\right)$ Reactíons \\ Measurements of the $(n, X \gamma)$ reaction} have been carried oul at energies extending from $1.09 \mathrm{MeV}$ to $14.8 \mathrm{MeV} .^{125}$ Since the measurements did not extend 
down to zero gamma ray energy, it was necessary to make an extrapolation in order to obtain $(n, X \gamma)$ cross st=ctions that reflect the entire gamma ray spectrum. This extrapolation to zero gamma ray energy was made on the basis of overall energy conservation (see Section $\mathrm{V}: \mathrm{C}$ ), and also by comparing the ${ }^{238} \mathrm{U}(\mathrm{n}, \mathrm{X} \gamma)$ spectra ${ }^{125}$ to the ${ }^{235} \mathrm{U}(\mathrm{n}, \mathrm{X \gamma}$ ) spectra of Drake, ${ }^{130}$ which extend down to $0.25 \mathrm{MeV}$ photon energy.

The accuracy of the gamma ray production cross section is estimated to be about $30 \%$ over the range of energies in the evaluation.

\section{Gamma Ray Production Angular Distributions}

There are no data on gamn:a ray angular distributions in ${ }^{238} \mathrm{U}$. However, measurements on other heavy elements indicate that the gamma ray production is essentially isotropic. Hence isotropy was assumed for all gamma-producing reactions.

\section{Gamma Ray Energy Distributions}

A. Gamma Energy Distributions

\section{from Neutron Capture}

The capture gamma ray energy spectrum has been reliably measured only at thermal neutron energies, 127 as was discussed in Section V:A. If the thermal neutron capture gamma ray spectrum is used at higher neutron energies, then in order to conserve energy we must either increase the multiplicity or else harden the spectrum. When the thermal spectrum is plotted on a linear scale (instead of the usual semi-logarithmic representation), it can be seen that the high energy tip of the spectrum is vanishingly small. Thus it is not feasible to conserve energy by extending the miniscule high energy tip of the spectrum. It is necessary to modify other parts of the spectrum as well. In the absence of data, we chose the simplest way; we shanged the multiplicity. The multiplicity and the high energy cutoff could both be modified, of course, but such complexity is unwar- ranted without more complete experimental data.

B. Gamma Energy Distributions from Fission Reactions

As discussed in Section $V: C$, the ${ }^{235} \mathrm{U}$ thermal fission gamma ray spectrum was also used for ${ }^{238} \mathrm{U}$, with the multiplicity held constant at the ${ }^{235}{ } T$ value for all incident neutron energies.

\section{Gamma Energy Distributions from $\left(n, n^{\dagger}\right)$ Reactions}

Gamm, rays from the 50 and $150 \mathrm{keV}$ inelastic levels were treated as line spectra. Gamma rays from the higher $\left(n, n^{\prime}\right)$ levels were placed in broad energy bins in a manner that conserved energy for the total neutrun scattering reaction.

\section{Gamma Energy Distributions from (n, Xr) Reactions}

Experimental measurements of the (n, $X \gamma$ ) cross section included measurements of the gamma ray spectra. ${ }^{125}$ The 
experimental spectra extended down to $0.5 \mathrm{MeV}$ photon energy. Extension to zero photon energy was made by com. paring to the data of Drake ${ }^{130}$ and by requiring overall energy conservation. At $1.09 \mathrm{MeV}$, detailed calculations of gamma ray contributions (rom $(n, \gamma)$. ( $n$, fission), and $\left(n, n^{\prime}\right)$ reactions were summed to give the proper shape for the low energy part of the $(n, X y)$ spectrum.
A small high-energy tail was also added to each spectrum to allow for the (experimentally unobservedl lission gamma ray contribution to the overall $(n, x y)$ spectrum.

'he overall accuracy of gamma ray spectra is about 30 in in the intddle portions of the spectra, with possible errors being much larger at very low and very high photon energies.

\section{Integral Tests of the Evaluation}

The only realistic estimate of the quality of evaluated nuclear data comes from calculating parameters of appropriate integral experiments and comparing the results with the corresponding measurements of those parameters. ${ }^{131}$ Unfortunately, an unequivocal certification of the validity of the complete evaluation is never possible since there is an intimate coupling of the effects of uncertainties in the quantities being tested. One is left then with the situation that the results of integral data testing can be used to indicate that an evaluation is poor, but they can not be used to certify that an evaluation is good. Furthermore, there exist no integral experiments sufficiently precise to test the evaluation over all incident particle energy regimes.

Among integral experiments, one must also differentiate between those which test an evaluated library and those which can be used to test a specific material. Those integral experiments which are made up of combinations of materials, each in a substantial fraction of the whole, can test only the general quality of an entire evaluated library, since no one material can dominate. This is especially true for critical issemblies. On the other hand, there are relatively few onematerial integral neutron experiments, possible exceptions being poor-geometrybroomstick-target experiments (which

Table 2. $\mathrm{K}_{\text {ff }}$ calculetions for 11 simple spherical critical assemblies in which the reflectors were uranium and the cores were ${ }^{233} \mathrm{U}$, ${ }^{235} \mathrm{U}$ or ${ }^{239} \mathrm{Pu}$.

\begin{tabular}{|c|c|c|c|}
\hline $\begin{array}{l}\text { Renlector } \\
\text { thickness } \\
\text { (cm) }\end{array}$ & $\begin{array}{c}\text { Core } \\
\text { material }\end{array}$ & $\mathbf{k}_{\text {eff }}{ }^{a}$ & $\begin{array}{c}\Delta k_{\text {eff }} \\
\text { calc }\end{array}$ \\
\hline 2. 30 & ${ }^{233} \mathrm{U}$ & 0.999 & \pm 0.003 \\
\hline 5.31 & ${ }^{233} \mathrm{U}$ & 1.004 & \pm 0.003 \\
\hline 19.91 & $233_{\mathrm{U}}$ & 0.998 & \pm 0.003 \\
\hline 1.76 & ${ }^{235} \mathrm{U}$ & 1.306 & \pm 0.003 \\
\hline 4.47 & $235 \mathrm{U}$ & 1.010 & \pm 0.003 \\
\hline 9.96 & ${ }^{235} \mathrm{U}$ & 1.004 & \pm 0.003 \\
\hline 18.10 & $235 \mathrm{U}$ & 1.002 & $t 0.003$ \\
\hline 1.93 & ${ }^{239} \mathrm{Pu}$ & 0.995 & \pm 0.003 \\
\hline 4.13 & ${ }^{239} \mathrm{Pu}$ & 1.004 & \pm 0.003 \\
\hline 6.74 & ${ }^{239} \mathrm{Pu}$ & 1.002 & \pm 0.003 \\
\hline 19.60 & ${ }^{239} \mathrm{Pu}$ & $i .002$ & \pm 0.003 \\
\hline - $-i_{i=1}$ & & 11.026 & \\
\hline
\end{tabular}


test primarily the minima in the total cross section) and the LLL pulsed spheres.

The above comments are made to put the problem of "evaluating an evaluation" into proper perspective, not to indulge in "hand-wringing." Integral testing of evaluations is a valid activity, but it should be carried out with the understanding that the results are not definitive.

To test the present evaluation of ${ }^{238} \mathrm{U}$ neutron reaction data, $k_{\text {eff }}$ values were calculated for 11 spherical assemblies in which reflectors of ${ }^{238} \mathrm{U}$ (natural uranium) reflected cores of ${ }^{235} \mathrm{U},{ }^{233} \mathrm{U}$ and ${ }^{239} \mathrm{Pu}$. The results are presented in Table 2.

The uncertainty in $k_{\text {eff }}$ resulting from uncertainties in the calculational models of the critical assemblies is usuai!y about $0.7 \%$. An analogue Monte Carlo neutronics code (TART) performed the $k_{\text {eff }}$ calcilations. Reaction cross sections are represented by 175 histograms on a standard preselected energy grid. Angular distributions of secondary neutrons are represented, at the incident energies supplied by the evaluator, by 32 intervals of equal probability in the cosine of the emission angle. Linear interpolation in energy at thes: cosine values is carried out by tine neutronics cod o obtain angular distributions at ar itrary energies. Energy distributions for secondary nonelastic neutrons are represented by 32 equally-probable increments in secondary energy, except for the fission process where 256 equally probable increments are used. Interpolations are as with angular distributions. The number of groups used for the cross sections, and the number of intervals used for angular and energy distributions, are adequate in the sense that increasing the number of increments does not affect the $k_{\text {eff }}$ calculations. The Monte Carlo statistics for the calculation are the values listed in the column of Table 2 headed $\Delta k_{\text {eff }}$. These represent a $67 \%$ confidence limit; when they are combined with the mass and geometry uncertainties in the critical assembly specifications, the result is tivat any calculated $k_{\text {eff }}$ value between 0.99 and 1.01 represents the "just critical" configuration as well as would a value of 1.0000 .

There is no reason to assume that the specifications of the critical assembly masses or geometrical configurations contain a built-in bias. Since neither the evaluations for the core materials nor those for ${ }^{235} \mathrm{U}$ have been adjuited to force agreement with critical assembly calculations, deficiencies in assembly specifications or in reflector material evaluations can be averaged out by consiciering the $11 \mathrm{k}_{\mathrm{ef}_{\mathrm{i}}^{x}}$ calculations of Table 2 as a whole (the evaluations used for the core materials are those in the ILL evaluated library). This leaves the ${ }^{238} \mathrm{U}$ evaluated data as the only common factor among the various calculations. The $\overline{k_{\text {eff }}}$ value of 1.0024 presented at the end of Table 2 then tends to provide a measure of the validity of the ${ }^{238} \mathrm{U}$ evaluation for fast and moderately fast neutronics systems.

In addition to the calculated $\mathbf{k}_{\text {eff }}$ values, time spectra of neutrons from a $14 \mathrm{MeV}$ pulsed sphere ${ }^{132}$ were also calculated for detectors placed at $30^{\circ}$ and $120^{\circ}$ with respect to the incident deuteron beam. The results are displayed in Figs. 1 and 2. The agreement with experiment is generally within calculational statistics except at the fis st minimum and for late arrival times, where disagreements 


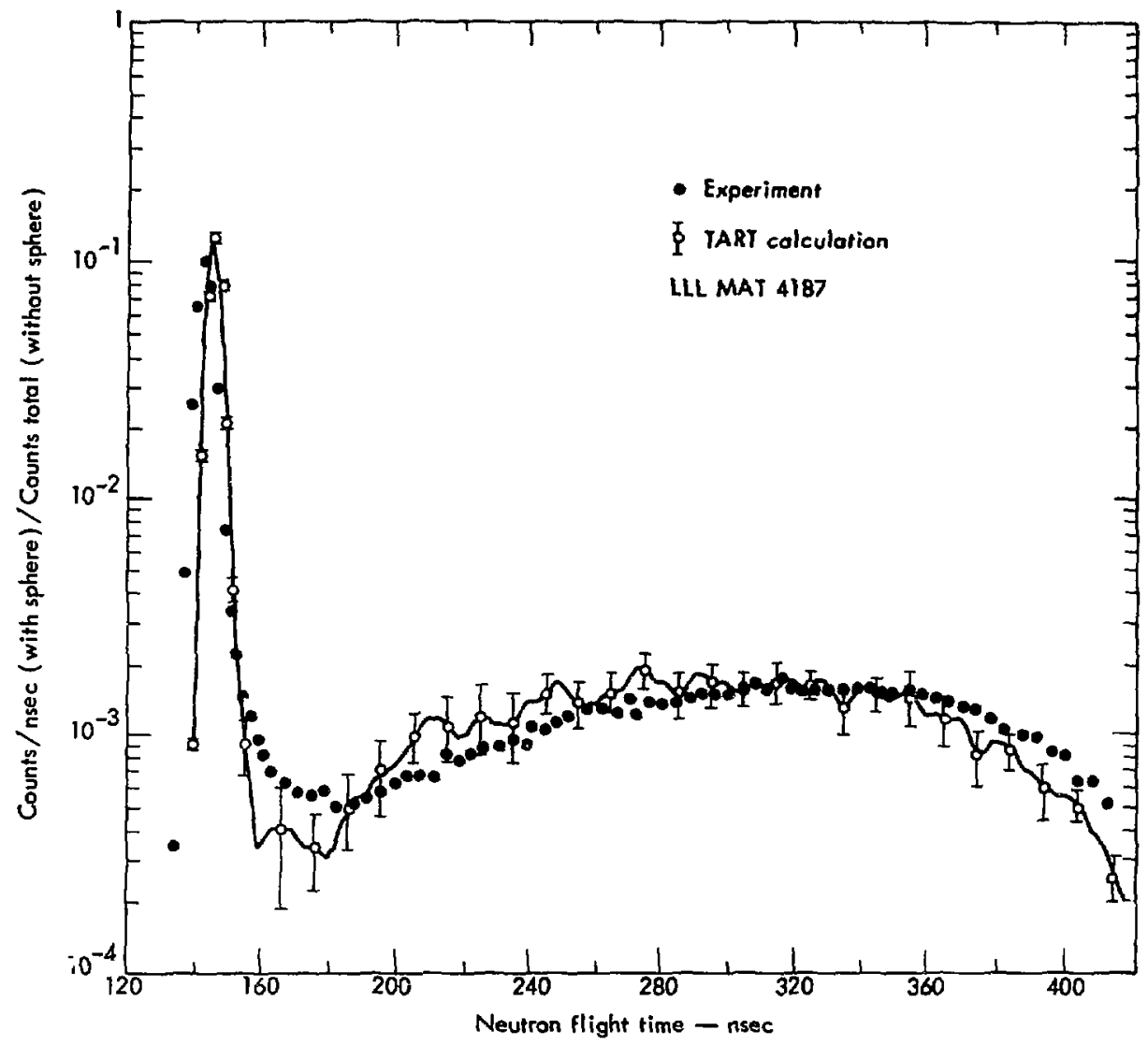

Fig. 1. A comparison of the experimental neutron spectrum from a 14-MeV pulsed sphere of $23 B_{U}$ vs that calculated using evaluated nuclear data (MAT 4187 ). The detector was at $30^{\circ}$ with respect to the incident deuteron beam.

between calculation and experiment are as much as a factor of two for the latest arrival times.

The apparent disagreement in the first minimum is not real. This calculation includes no correction for collimator inscattering. In other calculations the contribution of this correction amounts to the apparent discrepancy.
The question remains whether the disagreements between calculation and experiment are acceptable. To provide a basis for judging the acceptability of this evaluation, we present corresponding pulsed sphere calculations usitig ENDF/B-III (MAT 1158) cross sections in Figs. 3 and 4. Comparison with Figis. 1 and 2 clearly shows the improved agreement. 


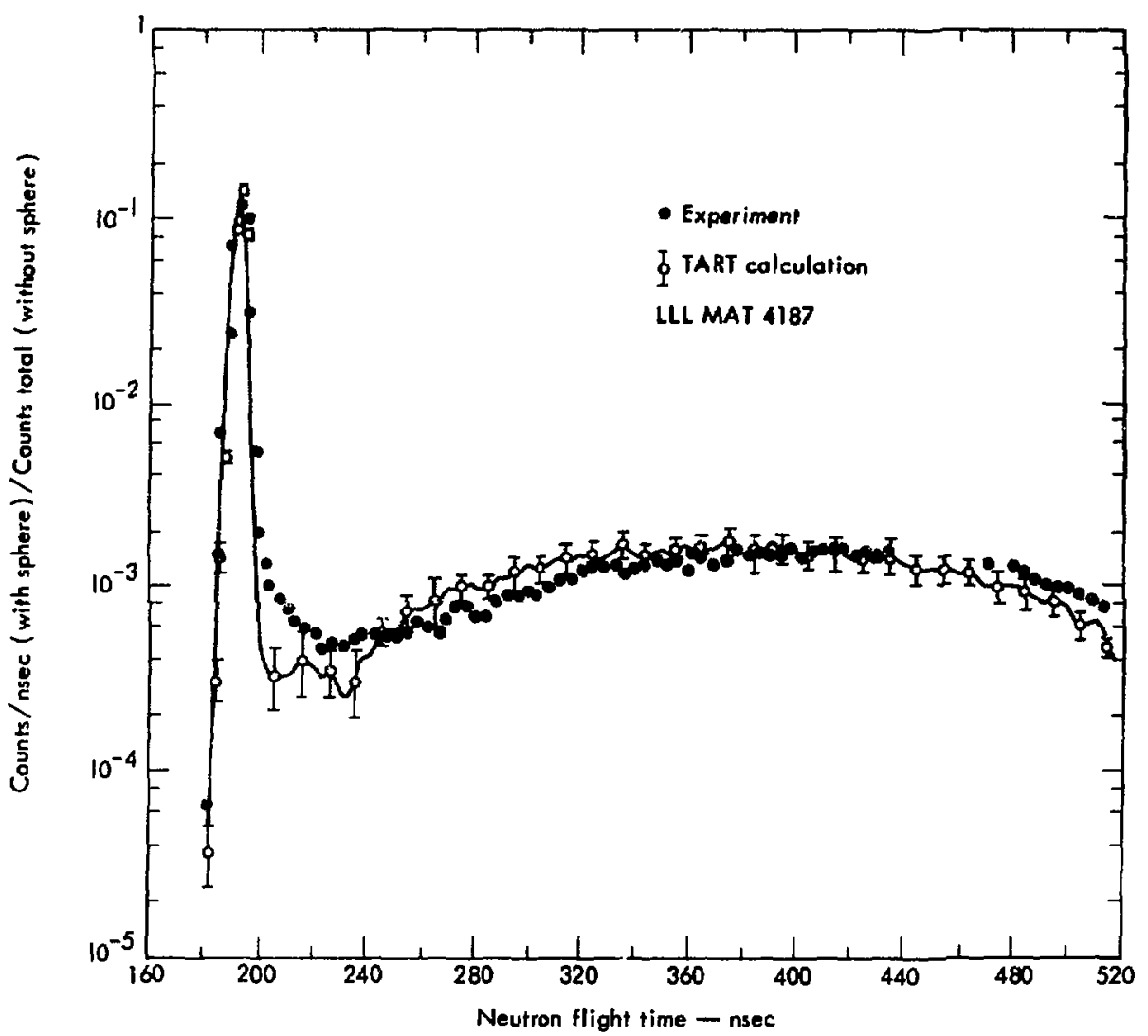

Fig. 2. A comparison of the experimental neutron spectrum froin a $14-\mathrm{MeV}$ pulsed sphere of 238 Us that calculated using evaluated nuclear data (MA T 4187). The detector was at $120^{\circ}$ with respect to the incident deuteron beam. 


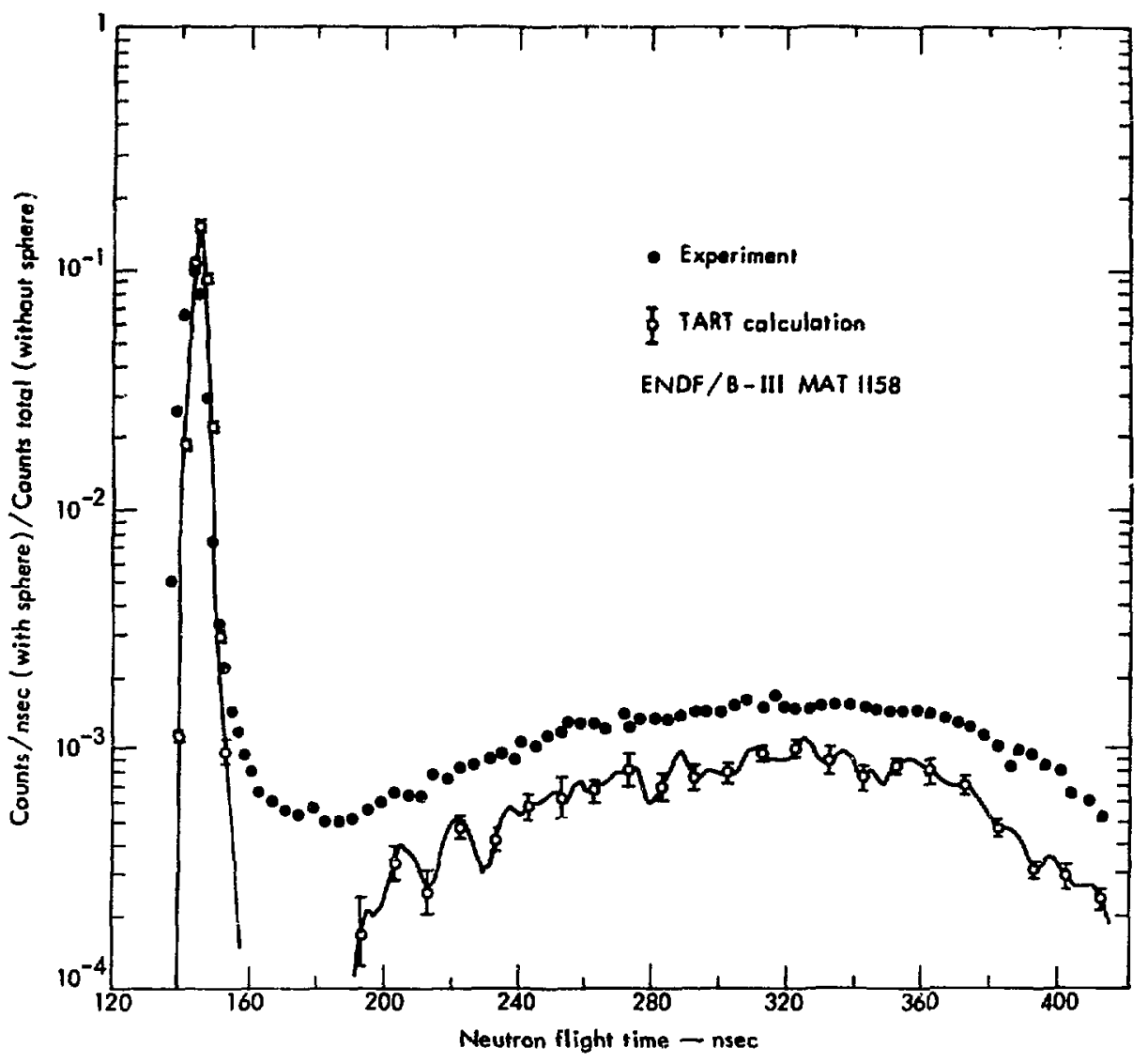

Fig. 3. A comparison of the experimental neutron time spectrum from a 14-MeV pulsed sphere of $238 \mathrm{U}$ vs that calculated using ENDF/B-III evaluated nuclear data (MAT 1158). The detector was at $30^{\circ}$ with respect to the incident deuteron beam. 


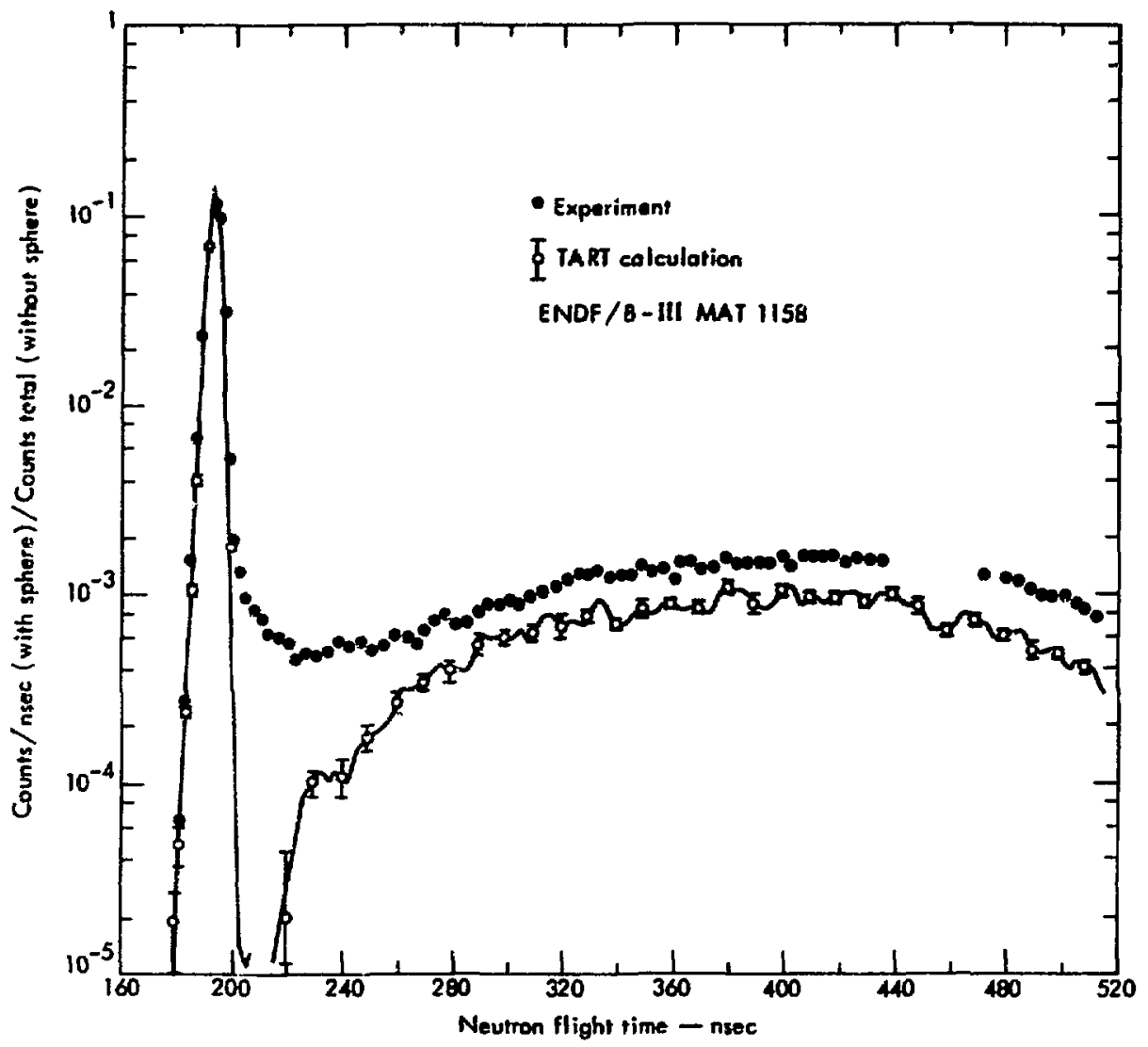

Fig. 4. A comparison of the experimental neutron time spectrum from a $14-\mathrm{MeV}$ pulsed sphere of $238 \mathrm{U}$ vs that calculated using ENDF/B-III evaluated nuclear data (MAT 115U). The detector was at $120^{\circ}$ with respect to the incident deuteron beam. 


\section{Reforencee}

1. H. Palevsky, R. S. Carter, and D. J. Hughes, Brookhaven National Laboratory, Rept. BNL-222 (1953).

2. W. W. Havens, Jr., Columbia University, private communication (1951); data taken from BNL-325 (1953).

3. L. M. Bollinger, R. E. Cote, D. A. Dahlberg, and G. E. Thomas, Phys, Rev. 105, 661 (1957).

4. K. K. Seth, D. J. Hughes, R. L. Zimmerman, and R. C. Garth, Phys. Rev. $110.692(1958)$.

5. J. B. Garg, J. Rainwater, J. S. Petersen, and W. W. Havens, Jr., Columbia University, private communication (1965). See also Phys. Rev. 137, 547 (1965); Phys. Rev. 136, 177 (1964): Phys. Rev. 134, 985 (1964); Nuclear Structure Study with Neutrons, Antwerp, Paper's 74 and 95 (1965); EANDC(US) -5*L (CR-1860) (1964); S. Wynchank, J. B. Garg, W. W. Havens, Jr., and J. Rainwater, Phys. Rev. 166, i 234 (1968).

6. M. L. Yeater, Knolls Atomic Power Laboratories, private communication (1956).

7. F. W. K. Firk, J. E. Lymn, and M. C. Moxon, Nucl. Phys. 41, 614 (1963).

8. C. T. Hibdon, and A. Langsdorf, Jr., Argonne National Laboratory, Rept. ANL-5175 (1954).

9. C. A. Uttley, C. M. Newstead, and K. M. Diment, IAEA Conference on Nuclear Data, Paris, Paper CN-23/36 (1966).

10. K. K. Seth, Duke University, private communication (1964).

11. J. F. Whalen, Argonne Natioral Laboratory, Argr ane, Ill,, private communication (1969).

:2. L. A. Galloway, III, Case Institute TID +1005 (1960).

13. A. B. Smith, Argonne National Laboratory, Argonne, Ill. private communisation (1969).

14. R. Batchelor, W. B. Gilboy, and J. H. Towle, Nucl. Phys. 65, 236 (1965).

15. D. G. Foster, Jr. and D. W. Glasgow, Hanford Works, Richland, Wash., private communication (1967): see also: HW-73116 (1962) and HW-77311 (1953).

16. C. Thibault, Centre d'Etudes rJucleaires, Saclay, Rept. CEA-R-3124 (1967).

17. A. Bratenahl, J. M. Peterson, and J. $T$. Stoering, Lawrence Livermore Laboratory Rept. UCRL-4980 (1957); see also, Phys, Rev. 110, 927 (1958).

18. i. Voignier, Commissariat a I'Energie Atomique, Rept. CEA-R-3403 (1968).

19. D. Didier, J. Phys. Radium 22, 149 (1961).

20. J. M. Peterson, A. Bratenahl, and J. P. Stoering, Phys. Rev, 120, 521 (1960).

21. R. H. Hildebrand and C. E. Leith, Phys. Rev, 80, Bi2 (1950).

22. J. DeJuren and N. Knable, Phys. Rev. 77, 606 (1950).

23. R. J. Schneider and A. M. Cormack, Nucl. Phys. 119, 197 (1968). 
24. R. C. Allen, Phys. Rev. 105, 1796 (1957).

25. P. Olum, Los Alamos Scientific Laboratory, Los Al.3mos, N. M., Rept. MDDC-353 (LA-274) (1945); including unpublished data of S. Cohen, P. Olum, and V. Weisskopf. See aiso: H. A. Bethe, J. R. Beyster, and R. E. Carter, LA-1939 (1955); M. Walt, A/Conf. 2, 18 (1955).

26. V. N. Andrev, Soviet Progress in Neutron Physics (196i) (Russian text published by Gosatomizdat, Moscow, 1961: tr. by Consultants Bureau, New York, 1962), P. 211.

27. M. Walt, A/Conf. 2, 18 (1955); see also, H. A. Bethe, J. R. Beyster, and R. E. Carier, Los Alamos Scientific Laboratory, Los Alamos, N.M., Rept. LA-193G (1955).

28. T. Bonner, Rice University, unpublished (1955).

29. Yu, G. Degtyarev, At. Energ. 19, 456 (1965) (translated in J. Nucl. Energy, Parts A/B 20818,1966$)$.

30. W. P. Ball, R. Booth, and M. H. MacGregor, Lawrence Livermore Laboratory, Rept. UCRL-5217 and Supplement (1958); see also, Phys, Rev, 130, 1471 (1963); M. H. MacGregor, Lawrerce Livermore Laboratory, private communication (1963).

31. A. Y. Cohen, J. Nuc1. Energy, Parts A/B 14, 180 (1961).

32. Yu. G. Degtyarev and V. G. Nadtochii, At. Energ. 11, 397 (1961).

33. E. R. Graves, Los Alamos Scientific Laboratory, Los Alamos, N. M., Rept. LAMS-1300 (1951); see also, H. A. Beths, J. R. Beyster, and R. E. Carter, LA -1939 (1955).

34. A. B. Smith, Nucl. Phys. 47, 633 (1963); see also, Trans. Am. Nucl. Soc. 5, 363 (1962).

35. J. B. Hunt, J. C. Robertson, and T. B. Ryves, J. Nucl. Energy 23, 705 (1969).

36. V. S. Crockex, J. Nucl. Energy 1, 234 (1955).

37. H. Palevsky, R. S. Carter, and D. Hughes, Brook’łaven National Laboratory, Upton, N. J., unpublished (1955); see also J. A. Harvey, A/Conf. 4, 147 (1955).

38. M. Asghar, C. M. Chaffey, and M. C. Moxon Nucl. Phys. 85, 305 (1966).

39. M. C. Moxon, Atomic Energy Research Establishment, Harwell, Rept. AERE-R$6074(1969)$.

40. A. D. Carlson, Gulf General Atomics, San Diego, Calif., private communication (1970); see also: M. P. Fricke, W. M. Lopez, S. J. Friesenhah.,, A. D. Carlson, and D. G. Costello, Nuclear Data for Reactors, Helsinki, 2, 265 (1970); GA-8835 (1968).

41. R. P. Schuman, Idaho Nuclear Corp., Rept. WASH-1127 (1969), p. 72; see also, WASH-1127 (1968), p. 66.

42. E. G. Bilpuch, L. W. Weston, and H. W. Newson, Ann. Phys. 10, $455(1960)$; see also, Bull. Am. Phys. Soc. 2, 218 (1957).

43. G. A. Linenberger and J. A. Miskel, Los Alamos Scientific Laboratory, Los Alamos, N. M., Rept. LA-467 (1946). 
44. M. C. Moxon, Atomic Energy Research Establishment, Harwell, private communication (1963); data received from CCDN.

45. R. L. Macklin and J. H. Gibbons, Oak Ridge National Laboratory, Oak Ridge, Tenn., private communication (1964); via BNL Sigma Center.

46. V. A. Tolstikov, L. E. Sherman, and Yu Ya. Stavisskii, At. Energ. 15, 414 (1963).

47. I. Bergquist, Arkiv Fysik 23, 425 (1962).

48. L. B. Miller and W. P. Poenitz, Nucl. Sci. Eng. 35, 295 (1969).

49. R. L. Macklin, N. H. Lazar, and W. S. Lyon, Phys. Rev. 107, 504 (1957).

50. H. O. Menlove and W. P. Poenitz, Nucl. Sci. Eng. 33, 24 (1968); see also, Fast Reactor Physics, Karlsruhe, 1, 67 (1967); W. P. Poenitz, D. Kompe, H. O. Menlove, and K. H. Beckurts, EURFNF-404 (1967); EANDC(E)-8חAL; IAEA Conference on Nuclear Data, Paris, Paper CN-23/10 (1966) for earlier data which is now superseded.

51. T. S. Belanova, At. Energ. 8, 549 (1960).

52. R. C. Hanna and B. Rose, J. Nucl. Energy 8, 197 (1959); see also, B. Rose, AERE-NF/R-1743 (1955).

53. W. F. Poeritz, Trans. Am. Nucl. Soc. 12, 279 (1969).

54. G. DeSaussure, L. W. Weston, J. D. Kington, R. D. Smiddie, and W. S. Lyon, Oak Ridge National Laboratory, Oak Fidge, Tenn., Rept. ORNL-3360, p. 51 (1962).

55. J. H. Gibbons, R. L. Macklin, P. D. Miller, and J. H. Neiler, Phys. Rev. 122 182 (1961): see also, Bull. Am. Phys. Soc. 4 , 385 (1959).

56. R. L. Macklin, J. H. Gibbons, and T. Inada, Phys. Rev. 129, 2695 (1963).

57. J. F. Barry, J. Bunce, and P. H. White, J. Nucl. Energy, Parts A/B, 18, 481 (1964).

58. 3. C. Diven, J. Terrell, and A. Hemmendinger, Phys, Rev. 120, 556 (1960).

59. W. S. Lyon and R. L. Macklin, Phys. Rev. 114, 1619 (1959).

ó0. A. I. Leipunsky, O. D. Kazachkovsky, G. Y. Artyukov, A. I. Baryshnikov,

T. S. Belanova, V. I. Galkov, Yu. Ya. Stavisskii, E. A. Stumbur, and

L. E. Sherman, A/Conf. 15, 50 (1958).

61. E. Broda and D. H. Wilkinson, Cavendish Laboratory, Oxford, England, Rept. BR-574 (1945), see also, J. Nucl, Energy g, 197 (1959).

62. J. L. Perkin, L. P. O'Connor, and R. F. Colenan, Atomic Weapons Research Establishment, Aldermaston, Rept. AWRE-O-59/57 (1957); see also, Proc. Phys. Soc. (London) 72, 505 (1958).

6:. L. J. Cook, E. M. McMillan, J. M. Peterson, and D. C. Sewell, Phys. Rev. $\underline{75}$, 7 (1949).

64. R. K. Smith, R. L. Henkel, and R. A. Noilles, Los Alamos Scientific Laboratory, Los Alamos, N. M., private communication (1958); see also, Bull. Am. Phys. Soc. 2, 196 (1957). There is also a private communication from R. K. Smith 
(1961). U25 and U2C Cross Sections corrected for scattering and renormalized by R. K. Smith (1968).

65. W. D. Allen and A. T. G. Ferguson, Proc. Phys. Soc. (London) 70, 573 (1957).

66. F. Netter, Centre d'Etudes Nucleaires, Saclay, private communication (1956).

67. J. A. Grundl, Nucl. Sc . Eng. 30, 39 (1967).

68. R. L. Henkel, Los Alamos Scientific Laboratory, I.os Alamos, N. M., Rept, LA-2114 (1957); see also: H. H. Barschal! and R. L. Henkel, LA-1714 (1954);

R. L. Henkel, LA-2122 (1957).

69. W. E. Stein, R. K. Smith, and H. L. Smith, Conference on Neutron Cross Section Technology, Wash. D. C., P/D-19 (1968); see also. Conference on Neutron Cross Section Technology, Wash. D. C., P/D-6 (1966).

70. V. Emma, S, Lonigro, C. Milone, and R. Ricamo, Nucl. Phys. 63, 641 (196j).

71. P. H. White and G. P. Warner, J. Nucl. Energy 21, 671 (1967); see also, CNR/PR-6, 20 (1965); CNR/PR-3, 22 (1964); EANDC(UK)-77S.

72. S. ‥ Kalinin and W. M. Pankratov, A/Conf. 16, 136 (1958).

73. V. M. Pankratov, At. Energ. 14, 177 (1963).

74. V. M. Pankratov, N. A. Vlasov, and B. V. Rybakov, At. Energ. 9, 399 (1960); translated in Sov. J. At. Energy 9, 936 (1961) and J. Nucl. Energy 16, 494 (1962).

75. M. D. Goldberg, W. S. Hall, and J. M. LeBlanc, Lawrence Livermore Laboratory, private communication (1957).

76. B. Adams, R. Batchelor, and T. S. Green, J. Nucl. Energy, Parts A/B 14, 85 (1961).

77. P. Billaud, C. Clair, M. Gaudin, R. Genin, R. Joly, J. L. LeRe 7, A. Michaudon, J. Ouvry, C. Signarbieux, and G. Vendryes, A/Conf. 16, 176 (1958), Paper $P / 1186$.

78. W. M. Webster, Lawrence Livermore Laboratory, private communication (1969).

79. M. Mangialajo, F. Merzari, and P. G. Sona, Nucl. Phys. 43, 124 (1963).

80. W. Nyer, Los Alamos Scientific Laboratory, Los Alamos, N. M., Rept. LA - 719 (1948).

81. C. A. Uttley and J. A. Phillips, Atomic Energy Research Establishment, Harwell, Rept. AERE-NP/R-1996 (1956).

82. R. C. Barrall, J. A. Holmes, and M. Sillbergeld, Air Force Weapons Laboratory, Palo Alto, Calif., Rept. AFWL-TR-68-134 (1969).

83. N. N. Flerov, A. A. Berezin, and I. E. Chelnokov, At. Energ. 5,657 (1958) (translated in J. Nucl. Energy, Part A, 11, 173 (1958) and Sov. J. At. Energy $\underline{\mathbf{5}}$, 1600 (1958).

84. V. I. Goldamskii, E. Z. Tarumov, and V. S. Penkina, Dokl. Akad. Nauk S.S.S.R. 101, 1027 (1955).

85. R. Batchelor, Proc. Phys. Soc. (London) 69, 214 (1956).

86. L. Rosen and L. Stewart, Los Alamos Scientific Laboratory, Los Alamos, N. M., Rept. LA-2111 (1957); older LASL data also presented here [unpublished and also LA-1532(1953)]. 
87. K. W. Allen, P. Bomyer, ani J. L. Perkin, J. Nucl. Energy, Furts A/B. 14, 100 (1961).

88. R. L. Clarke, Can. J. Phys. 39, 957 (1961).

89. P. H. White, J. Nucl. Energy, Parts A/ 16, (1962).

90. L. G. Stromberg and S. Schwarz, Nucl. Phys. 71, 511 (1965); see also, NP-15012 (1965).

91. D. Barr, Los Alamos Scientific Laboratory, Los Alamos, N. M., private communication (1966); see also, J. D. Knight, R. K. Smith, and B. Warren, Phys. Rev. 112, 259 (1958); J. D. Knight, R. K. Smith, R. A. Nobles, and B. Warren, Bull. Am. Phys. Soc. 2, 198 (1957).

92. D. S. Mather, Atomic Weapons Research Establishment, Aldermaston, private communication (1969).

93. D. S. Mather and L. F. Pain, Atomic Weapons Research Establishment, Aidermaston, Rept. AWRE-O-47/69 (1969).

94. J. A. Phillips, Atomic Energy Research Establishment, Harwell, Rept. AERENP/R-2033 (1956).

95. J. L. Ferkin and R. F. Coleman, J. Nucl. Energy, Parts A/B, 14, 69 (1961).

96. G. P. Antrcnov, Yu. A. Zysin, A. A. Kovrizhnykh, and A. A. Lbov, At. Energ. 5, 456 (1958) (translated in J. Nucl. Energy, Part A 10, 184 (1959)).

97. E. Barnard, A. T. G. Ferguson, W. R. McMurray, and I. J. Van Heerden, Nucl. Phys. 80, 46 (1966).

98. L. Cranberg and J. S. Levin, Phys. Rev. 109, 2063 (1958).

99. R. Batchelor and J. H. Towle, Proc. Phys. Soc. (London) 73, 193 (1959).

100. L. Cranberg and J. S. Levin, Phys. Rev. 103, 343 (1956).

101. E. Barnard, A. T. G. Ferguson, W. R. McMurray, and I. J. Van Heerden, Nucl. Phys. 71, 228 (1965).

102. R. J. Howerton, Nucl. Sci. Eng. 46, 42 (1971).

103. R. J. Howerton and R. J. Doyas, Nucl.Sci. Eng. 46, 414 (1971).

104. E. Segre, Fhys. Rev. 86. 21 (1952).

105. R. Richmond and B. J. Gardner, Atomic Energy Research Establishment, Harwell, Rept. AERE-R/R-2097 (TNCC(UK)12) (1957).

106. E. K. Gerling and Yu. A. Shukolyukov, At. Energ. 8, 49 (1960).

107. B. D. Kuz'minov, L. S. Kutsaeva, V. G. Nesterov, L. I. Prokhorova, and G. P. Smirenkin, Zh. Eksperim. i Teor. Fiz. 37, 407 (1959).

108. R. Sher and J. Leroy, J. Nucl. Energy, Part A 12, 101 (1960).

109. K. W. Seiger and D. C. Rose, Can. J. Phys. 32, 498 (1954).

110. I. Asplund-Nilsson, H. Conde, and N. Starfelt, Nucl. Sci. Eng. 15, 213 (1963).

111. M. Soleilhac, J. Frehaut, J. Gauriau, M. Labat, and J. Perchereau, Centre d'Etudes de Brugeres le Chatel (France) private communication (1968); see also EANDC(E)-76U, p. 186 (1967); J. Nucl. Energy 23, 257 (1969).

112. D. S. Mather, P. Fieldhouse, and A. Moat, Nucl, Phys. 66, 149 (1965); see also, EANDC(UK) $-49 \mathrm{~S}$. 
113. I. Asplund-Nilsson, H. Cunde, and N. Starfelt: Nucl. Sci. Eng. 20, 527 (1964).

114. J. Terrell, Phys. Rev. Lett. 1, 783 (1957); data attributed to Diven, Martin, Taschek, and Terrell (unpublished).

115. D. Butler, S. Cox, J. Meadows, J. Roberts, A. Smith, and J. Whalen, Physics of Fast and Intermediate Reactors, Vienna, SM-18/36 (1961), Vol, 1, p. 125; see also, Phys. Rev. 123, 1735 (1961).

116. B. D. Kuz'minov, Soviet Progress in Neutron Physics, p. 177; (Russian text by Gosatomizdat, Moscow, 1961 - tr. by Consultants Bureau, New York, 1962).

117. I. Johnstone, Atomic Energy Research Establishment, Harwell, Rept. AERENP/R -1912 (1956).

118. H. Conde and N. Starfelt, Nucl. Sci. Eng. 11, 397 (1961).

119. H. A. Bethe, J. R. Beyster, and R. E. Carter, Los Alamos Scientific Laboratory, Los Alamos, N. M., Rept. LA-1939 (1955).

120. N. N. Flerov and V. M. Talyzin, At. Energ. $\underline{5}, 653$ (1958) (translated in J. Nucl. Energy, Part A 11, 169 (1960).

121. L-S Chung and M-T Lu, Chinese J. Phys. 1, 9 (1963).

122. 3. Blaise, M. Gaudin, R. Joly, J. Leroy, and G. Vendryes, J. Phys. Radium 19 , 66 (1958).

123. A. Moat, D. S. Mather, and M. H. Mc Taggart, J. Nucl. Energy, Parts A/B 15, $102(1961)$.

124. Yu. A. Vasil'ev, Yu. S. Zamyatnin, Yu. I. Il'in, E. I. Sirotinin, P. V. Toropov, and E. F. Fomushk'in, Zh, Eksperim. i Teor. Fiz. 38, 671 (1960) (translated in Soviet Pliys. JETP 11, 483 (1960).

125. P. S. Buchanan et al., Texas Nuclear Corp. Rept. ORo-2791-32 (1971).

126. J. John and V. J. Orphan, Gamma Rays from Resonant Capture of Neutrons in U238, Gulf Radiation Technology, Rept, GA-10186 (1970).

127. These thermal-neutron-capture gamma ray data are preliminary and have not yet been released for general publication.

128. R. W. Peelie and F. C. Maienschein, Phys. Rev. C 3, 373 (1971).

129. Y. A. Ellis, "Nuclear Data Sheets for $A=238, "$ Nuclear Data, Section $B \underline{4}$, $635(1970)$.

13n. D. M. Drake, Nucl. Phys. A133, 108 (1969).

131. V. E. Hampel, Evaluated Integral Neutron Experiments, Lawrence Livermore Laboratory, Rept. UCRL 50400 , Vol 8 (to be published).

132. C. Wong. J. D. Anderson, P. Brown, L. F. Hansen, J. L. Kammerdiener, C. Logan, and B. Pohl, Lawrence Livermore Laboratory, Rept. UCRI-51144, Rev. 1, Addendum (to be published). 